\title{
A new signal characterization and signal-based Chou's PseAAC representation of protein sequences
}

\author{
Victoria Sanchez*, Antonio M. Peinado ${ }^{\dagger}$, Jose L. Pérez-Córdoba \\ and Angel M. Gómez ${ }^{\S}$ \\ Department of Signal Theory \\ Networking and Communications \\ Universidad de Granada \\ 18071 Granada, Spain \\ *victoria@ugr.es \\ $\dagger^{\dagger} a m p @ u g r . e s$ \\ \$lpc@ugr.es \\ §amgg@ugr.es
}

Received 16 June 2015

Revised 31 July 2015

Accepted 3 August 2015

Published 25 September 2015

\begin{abstract}
Most of the algorithms used for information extraction and for processing the amino acid chains that make up proteins treat them as symbolic chains. Fewer algorithms exploit signal processing techniques that require a numerical representation of amino acid chains. However, these algorithms are very powerful for extracting regularities that cannot be detected when working with a symbolic chain, which may be important for understanding the biological meaning of a sequence or in classification tasks. In this study, a new mathematical representation of amino acid chains is proposed, which is derived using a similarity measure based on the PAM250 amino acid substitution matrix and that generates 20 signals for each protein sequence. Using this representation 20 consensus spectra for a protein family are determined and the relevance of the frequency peaks is established, obtaining a group of significant frequency peaks that manifest common periodicities of the amino acid sequences that belong to a protein family. We also show that the proposed representation in 20 signals can be integrated into Chou's pseudo amino acid composition (PseAAC) and constitute a useful alternative to amino acid physicochemical properties in Chou's PseAAC.
\end{abstract}

Keywords: Amino acid chain; mathematical representation; signal processing; protein family; pseudo amino acid composition.

\section{Introduction}

Traditionally, amino acid chains have been processed as symbolic chains where each amino acid is represented by a letter from a 20-element alphabet. Recently, signal

${ }^{*}$ Corresponding author.

This is an Open Access article published by World Scientific Publishing Company. It is distributed under the terms of the Creative Commons Attribution 4.0 (CC-BY) License. Further distribution of this work is permitted, provided the original work is properly cited. 
processing techniques have been introduced for the analysis of amino acid chains, where the symbolic chain is first converted into a numerical representation. Several approaches have been explored, including the so-called resonant recognition model $(\mathrm{RRM}){ }^{15}$ where a consensus spectrum is determined (resonance effects had also been studied in Refs. 7-9 and 24). Other approaches exploit signal processing tools such as Fourier ${ }^{26,27,58}$ or wavelet transforms, ${ }^{1,22,39,4148-50,55}$ digital filters, ${ }^{54}$ or spectral similarity measures. ${ }^{21}$ Another interesting approach uses signal processing techniques to detect remote homologs ${ }^{45}$ where the amino acid chains are represented by feature vectors determined from a spectral analysis, which are then combined with Hidden Markov Models (HMMs) in a similar manner to speech recognition tasks. ${ }^{43}$ This approach improves the traditional Profile HMMs (PHMMs) that use symbolic chains in classification tasks, as described by Ref. 45 .

Thus, in order to use signal processing methods, the symbolic chain must first be converted into a numerical representation. The most common numerical representations are based on the physicochemical or biochemical properties of amino acids, i.e. amino acid indices, ${ }^{23}$ where each index assigns a number to each amino acid, depending on the specific physicochemical or biochemical property that the index represents. This type of numerical representation is used in the RRM model, where the electron-ion interaction potential (EIIP) is often employed as an amino acid index. The EIIP of an amino acid is a physical property that represents the average energy of the valence electrons in the amino acid. After obtaining the EIIP representation of amino acid chains, the next step in the RRM model is to calculate the consensus spectrum. To achieve this, the discrete Fourier transform (DFT) of each protein is calculated and the consensus spectrum is obtained as the product of the amplitude spectra of the protein sequences that belong to a functional group. If a significant peak appears in the consensus spectrum, this means that the members of a group of proteins share a common biological function and the frequency of the peak is called the characteristic frequency. In Ref. 14, it was suggested that one significant peak appears for each biological function that the group of proteins share, but normally only one significant peak appears, and thus the protein group is represented by one characteristic frequency.

At the same time, with the explosive growth of biological sequence generated in the post-genomic age, one of the most important but also most difficult problems in computational biology is how to formulate a biological sequence with a discrete model or a vector, yet still keep considerable sequence pattern information. This is due to the fact that powerful operation engines, such as support vector machines (SVM) and neural networks (NN), can only handle vectors but not sequence samples, as elaborated in Ref. 13. However, a vector defined in a discrete model may completely lose all sequence-order information. To avoid completely losing the sequence-order or pattern information for proteins, the pseudo amino acid composition or PseAAC was proposed. Since the concept of Chou's PseAAC ${ }^{18,19}$ was proposed, it has been used in nearly all the areas of computational proteomics (see, e.g. a long list of references cited in two comprehensive reviews ${ }^{6,12}$ ). Due to its success in dealing with protein/peptide sequences in computational proteomics, the concept of Chou's 
PseAAC has been recently extended to deal with DNA/RNA sequences in computational genetics and genomics (see, e.g. Refs. 2-5, 20, 25, 33-38 and 51) and has been successfully applied to DNA binding protein identification ${ }^{29,31}$ and protein remote homology detection. ${ }^{28,30,32}$

In the present study, we first propose a mathematical representation of the amino acid chain that comprises a protein. This representation is based on a similarity measure, which is derived from the PAM250 amino acid substitution matrix, and it generates 20 signals for each amino acid sequence. 20 consensus spectra are then determined for a protein family and the relevant frequency peaks are determined, thereby yielding a characterization of the protein family based on the significant frequency peaks. This was used to characterize the 12 families that belong to the lysozyme clan (CL0037) in Pfam (Release 27.0, March 2013). ${ }^{46}$ We also performed a comparison with the EIIP representation and we assessed the extent to which current PHMMs are able to reproduce the main periodicities identified by our approach. We then propose a different feature vector to represent protein sequences by incorporating the signal-based information into Chou's PseAAC and study its performance for a classification task.

\section{Approach}

\subsection{Similarity measure and consensus spectrum}

We will first propose a mathematical representation of a protein sequence based on the relationships between the amino acids present in the amino acid substitution matrices. Thus, we consider the popular PAM250 amino acid substitution matrix. ${ }^{16}$ PAM matrices are based on an explicit evolutionary model and PAM250 is the mutation probability matrix for the evolutionary distance of 250 point accepted mutations (PAMs). A PAM in a protein is a replacement of one amino acid by another, which is accepted by natural selection, i.e. as stated in Ref. 16: "to be accepted, the new amino acid usually must function in a way similar to the old one; chemical and physical similarities are found between the amino acids that are observed to interchange frequently". Based on this idea of the degree of similarity between amino acids in PAM matrices, we formulate a mathematical representation of the amino acid chain that comprises one protein. This representation generates 20 signals: one for each of the 20 different amino acids that are normally considered. The signal that corresponds to one of the 20 amino acids is constructed to reflect the degree of similarity among all the amino acids in the chain to that particular amino acid. The measure of similarity is given by the relatedness odds matrix $\mathbf{R}$ and, in particular, the measure of similarity $\mathbf{y}_{i}=\left[y_{i}(1), y_{i}(2), \ldots, y_{i}(20)\right]$ between amino acid $i$ and each one of the 20 amino acids is given by the row $i$ of matrix $\mathbf{R}$, where the elements of this row are determined as

$$
y_{i}(j)=R(i, j)=\frac{P(i \mid j)}{P(i)}=\frac{M(i, j)}{P(i)} \quad j=1, \ldots, 20,
$$


where $M(i, j)$ is the mutation probability matrix and $P(i)$ is the a priori probability of amino acid $i . R(i, j)$ represents the probability that amino acid $i$ will replace amino acid $j$ or vice versa every time $i$ or $j$ is encountered in the sequence (per occurrence of $i$ per occurrence of $j$ ). Thus, in our case, we use the matrix $R(i, j)$ as a measure of similarity between the amino acids that belong to the same amino acid chain that comprises a protein, instead of using it as a measure of similarity between amino acids that belong to different proteins, which is normally the case.

Next, we describe how to construct a mathematical representation of a protein in the form of 20 signals, i.e. one signal for each amino acid. The signal $\mathbf{x}_{i}$ that corresponds to amino acid $i$ is built by considering the similarity of amino acid $i$ to each of the amino acids that comprise the protein. Let $\mathbf{a}=[a(1), a(2), \ldots, a(L)]$ represent the amino acid chain in the protein that we are considering, where $L$ is the number of amino acids in the protein. Then, the numerical sequence that constitutes signal $\mathbf{x}_{i}=\left[x_{i}(1), x_{i}(2), \ldots, x_{i}(L)\right]$ is built by substituting each amino acid $a(n)$ in the chain with the similarity of that amino acid, $y_{i}(a(n))$ (given by the relatedness odds matrix), to amino acid $i$, as follows.

$$
x_{i}(n)=y_{i}(a(n))=R(i, a(n)) \quad n=1, \ldots, L
$$

$\mathbf{x}_{i}$ is the signal corresponding to amino acid $i$ and we generate one signal for each amino acid $i=1, \ldots, 20$, finally obtaining 20 signals.

Next, we characterize a group of $Q$ proteins based on the 20 consensus frequency spectra associated with the 20 signals that represent each protein. In order to determine the consensus frequency spectrum $\mathbf{S}_{i}$ that corresponds to the group of $Q$ proteins and which is associated with amino acid $i$, we first calculate the $\mathrm{DFT}^{42}$ of each of the $Q$ signals that correspond to amino acid $i\left\{\mathbf{x}_{i, j}\right\}, j=1, \ldots, Q$, thereby obtaining $\mathbf{X}_{i, j}=\operatorname{DFT}\left(\mathbf{x}_{i, j}\right)=\left[X_{i, j}(1), X_{i, j}(2), \ldots, X_{i, j}(N / 2)\right]$, where we employ an $N$-point DFT. The consensus spectrum $\mathbf{S}_{i}=\left[S_{i}(1), \ldots, S_{i}(N / 2)\right]$ that corresponds to amino acid $i$ is then determined as

$$
S_{i}(k)=\prod_{j=1}^{Q}\left|X_{i, j}(k)\right|^{2} \quad k=1, \ldots, N / 2,
$$

where | | is the modulus. The group of proteins is then characterized based on the 20 consensus spectra $\left\{\mathbf{S}_{i}, i=1, \ldots, 20\right\}$.

\section{Methods}

Next, we explain how to use this representation to determine common regularities in a protein family. In this example, we considered all of the protein families that comprise the lysozyme clan (CL0037), as defined in Pfam (Release 27.0, March 2013). This clan contains 12 protein families, as shown in Table 1. This representation could have been applied to any protein families, but we prefered to select a 
Table 1. The 12 protein families that belong to the lysozyme clan (CL0037) in the Pfam database.

\begin{tabular}{c} 
CL0037 \\
\hline PF00062, PF00182, PF00959, PF01374, PF01464, PF01832 \\
PF05838, PF06737, PF06871, PF10715, PF13406, PF13702 \\
\hline
\end{tabular}

clan instead of an arbitrary set of protein families. We also chose this particular clan because it allows us to compare our method with previous results.

First, we determined the 20 consensus spectra $\left\{\mathbf{S}_{i}, i=1, \ldots, 20\right\}$ for the first protein family listed in Table 1 (PF00062) using the method described in the previous section. To determine these 20 consensus spectra, we used the 21 representative sequences in the seed alignment, which were obtained from Pfam (Release 27.0, March 2013) for the protein family. Next, we determined the frequency that corresponded to the most significant peak in each consensus spectrum. We performed a DFT of order $N=4096$ and the frequency that corresponded to the most significant peak, $k_{\max }$, was indicated by the value of $k$ with the maximum value in the corresponding $i$ th consensus spectrum $\left\{S_{i}(k), k=1, \ldots, N / 2\right\}$ (the corresponding frequency could be determined simply by $\left.f_{\max }=k_{\max } / N\right)$. The results obtained are shown in Table 2.

Table 2. Characterization of protein family PF00062.

\begin{tabular}{|c|c|c|c|c|c|}
\hline \multirow[b]{2}{*}{$\begin{array}{l}\text { Amino } \\
\text { acid }\end{array}$} & \multicolumn{5}{|c|}{ PF00062 } \\
\hline & $\begin{array}{c}k_{\max } \\
21 \text { seqs } \\
\text { SEED }\end{array}$ & $\begin{array}{c}\text { Count } 1000 \text { groups } \\
21 \text { seqs each } \\
\text { FULL }\end{array}$ & $\mathrm{S} / \mathrm{N}$ & $\begin{array}{c}k_{\max } \\
1035 \text { seqs } \\
\text { PHMM }\end{array}$ & $\begin{array}{c}\text { Count } 1000 \text { groups } \\
\text { 21seqs each } \\
\text { FULL }\end{array}$ \\
\hline $\mathrm{A}, 1$ & 1583 & 230 & 109.92 & 1175 & 16 \\
\hline $\mathrm{R}, 2$ & 884 & 207 & 349.43 & 714 & 17 \\
\hline $\mathrm{N}, 3$ & 169 & 31 & 229.71 & 1488 & 29 \\
\hline $\mathrm{D}, 4$ & 246 & 398 & 273.29 & 1490 & 9 \\
\hline $\mathrm{C}, 5$ & 973 & 186 & 242.68 & 244 & 213 \\
\hline $\mathrm{Q}, 6$ & 1470 & 256 & 235.04 & 1494 & 121 \\
\hline $\mathrm{E}, 7$ & 247 & 257 & 260.44 & 1490 & 22 \\
\hline $\mathrm{G}, 8$ & 149 & 318 & 274.04 & 1618 & 127 \\
\hline $\mathrm{H}, 9$ & 1150 & 6 & 100.94 & 957 & 8 \\
\hline $\mathrm{I}, 10$ & 1223 & 728 & 217.05 & 1229 & 714 \\
\hline $\mathrm{L}, 11$ & 804 & 200 & 263.93 & 966 & 0 \\
\hline $\mathrm{K}, 12$ & 1021 & 243 & 172.24 & 146 & 29 \\
\hline M, 13 & 56 & 166 & 254.54 & 920 & 86 \\
\hline $\mathrm{F}, 14$ & 911 & 255 & 278.25 & 1489 & 131 \\
\hline $\mathrm{P}, 15$ & 372 & 321 & 113.08 & 172 & 310 \\
\hline $\mathrm{S}, 16$ & 826 & 461 & 304.64 & 1619 & 255 \\
\hline $\mathrm{T}, 17$ & 1057 & 7 & 277.40 & 1176 & 6 \\
\hline W, 18 & 101 & 994 & 203.96 & 98 & 994 \\
\hline $\mathrm{Y}, 19$ & 482 & 143 & 256.44 & 1349 & 12 \\
\hline $\mathrm{V}, 20$ & 1221 & 772 & 242.21 & 1227 & 744 \\
\hline
\end{tabular}




\section{Sanchez et al.}

In order to illustrate the meaning of a high peak in the consensus spectrum, we performed the following experiment. We generated the sinusoid shown in Fig. 1(a) and its spectrum in 1(b) (where the frequency corresponds simply to $k / N$ ). In this spectrum, a significant peak can be observed at the frequency that corresponds to the sinusoid frequency $\left(k_{\max }=207\right)$. Next, we contaminated this sinusoid using additive noise with a Gaussian distribution, thereby yielding a signal with a very low signal-to-noise $(\mathrm{S} / \mathrm{N})$ ratio, which means that the power of the noise added to the sinusoid was much higher than the power of the sinusoid and this resulted in a highly distorted signal. In Fig. 1(c), we show an example of this signal and its spectrum (Fig. $1(\mathrm{~d})$ ) where the $\mathrm{S} / \mathrm{N}$ ratio is $-16.45 \mathrm{~dB}$. It can be seen that the most significant peak in the spectrum no longer corresponds to the frequency of the sinusoid and the underlying periodicity of the signal is hidden by the noise. Thus, a simple analysis of the spectrum of the signal would make it difficult to determine this hidden periodicity.

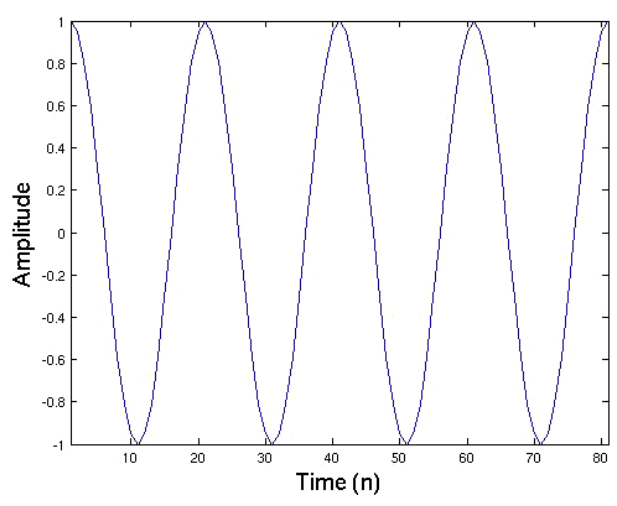

(a)

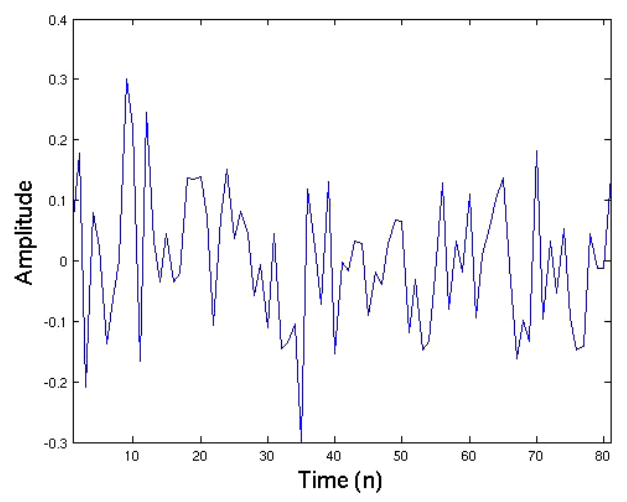

(c)

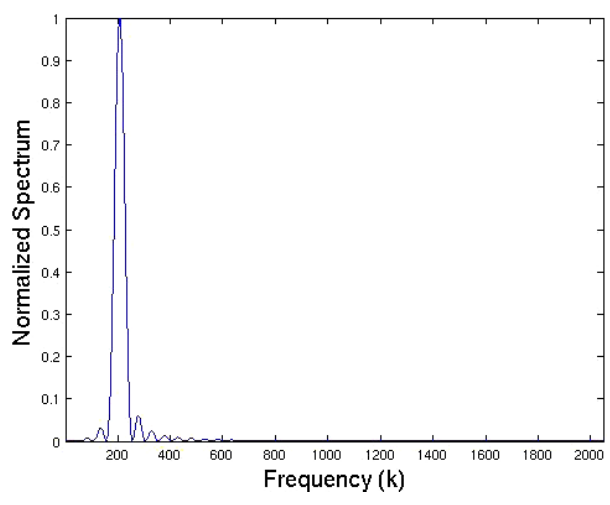

(b)

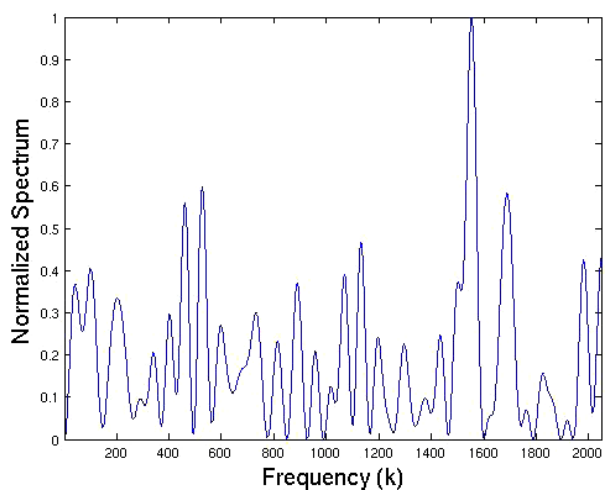

(d)

Fig. 1. (a) Sinusoidal signal. (b) Spectrum of the sinusoidal signal. (c) Sinusoidal of the signal with Gaussian additive noise. (d) Spectrum of the noisy sinusoid. 
Next, we generated 100 noisy sinusoidal signals as described above, all of which had an $\mathrm{S} / \mathrm{N}$ ratio of around $-16 \mathrm{~dB}$. In most cases, the most significant peak in each spectrum did not correspond to the underlying periodicity of the signal. However, we then determined the consensus spectrum of two of the 100 noisy signals using Eq. (3), where the $Q$ signals are now the two noisy sinusoidal signals. The consensus spectrum obtained for both signals is shown in Fig. 2(c), and the individual spectrum for each signal is shown in Figs. 2(a) and 2(b). As can be seen, when we determine the consensus spectrum of the two noisy signals the underlying common periodicity stands out and this fact is even more evident in the consensus spectrum of the 100 noisy signals (see Fig. 2(d)) although this periodicity is not clearly manifested in the individual spectrum of most of the noisy signals.

Given this example, we can now interpret each of the 20 signals that represent one protein as potentially containing some hidden regularity that is common to the protein family, but which might not be detected by an individual spectral analysis of

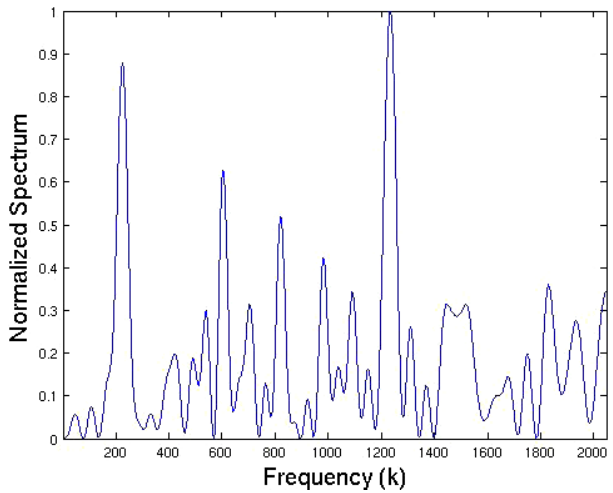

(a)

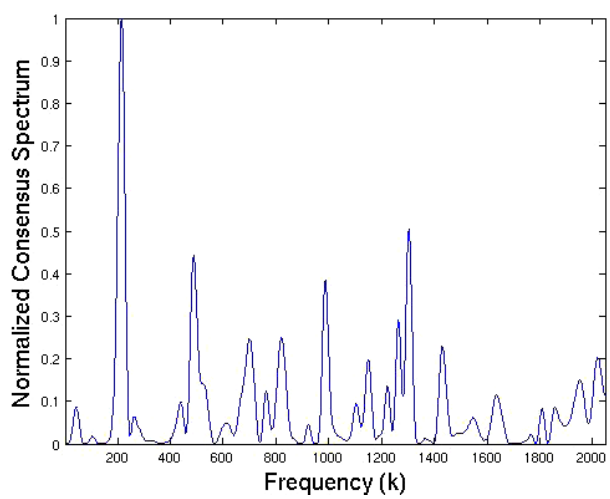

(c)

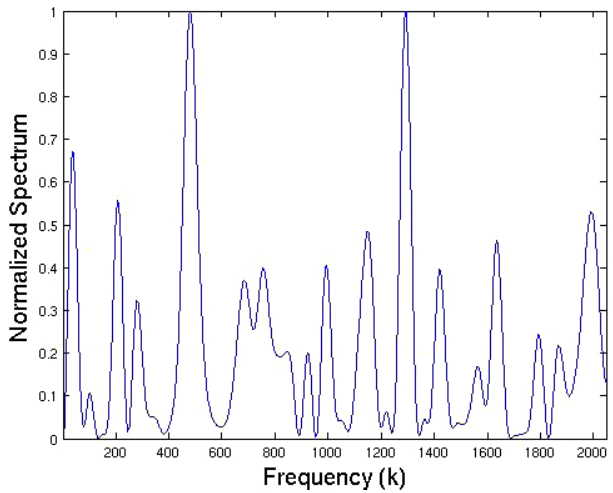

(b)

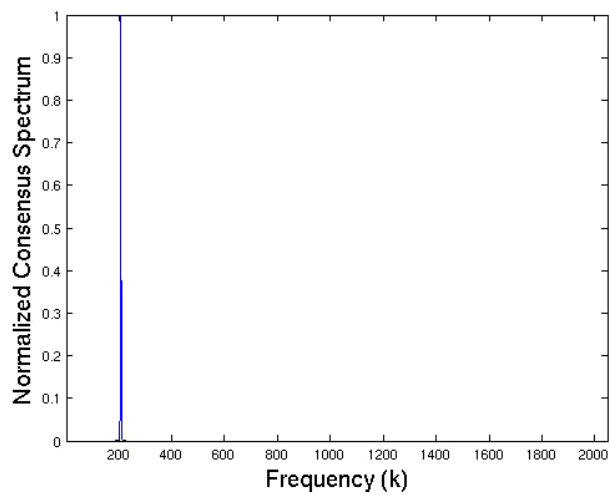

(d)

Fig. 2. (a) Spectrum of a noisy signal 1. (b) Spectrum of a noisy signal 2. (c) Consensus spectrum of noisy signals 1 and 2. (d) Consensus spectrum of 100 noisy signals. 
the signal, thereby requiring a joint spectral analysis of all the signals that belong to a family (where the individual differences among protein sequences are interpreted as noise). Thus, the frequency peak that corresponds to the maximum $k_{\max }$ of each of the 20 consensus spectra in a protein family could represent a common periodicity in the protein signals that correspond to the amino acid, but we are concerned with the extent to which this maximum actually represents a hidden periodicity in the signals that correspond to the amino acid in the overall protein family. To determine the significance of a certain frequency peak, we performed the following procedure. We considered 1000 groups of protein sequences which were taken from the sequences resulting from the full alignment performed in Pfam for a protein family. The number of protein sequences in each group was equal to the number of protein sequences used in the seed alignment for that family, and the particular sequences that formed each group were selected randomly with a uniform distribution (each protein sequence was as likely to be selected). We then determined the consensus spectrum for each amino acid and for each of the 1000 groups, while we also counted how many times the maximum of the consensus spectrum for each amino acid and for the 1000 groups coincided with that of the seed sequences $\left(k_{\max } \pm 20\right)$ for a specific amino acid. We considered that the corresponding peak was a significant peak when the count exceeded 500 .

For the PF00062 family, we obtained 1000 groups of 21 random protein sequences, where each protein sequence was taken from 1035 sequences, which comprised the full alignment of the family. The results obtained using the procedure described above are shown in Table 2, where the main frequency peaks are indicated in bold (count $>500$ ). These results show that the protein family is characterized by a number of significant frequency peaks, which appear at specific frequencies in several of the amino acid signals. For the PF00062 family, these main frequencies are $1221 \pm 20$ and $101 \pm 20$, which represent the common regularities of the protein family. The consensus spectrum of the corresponding amino acid signals of the seed sequences is shown in Fig. 3. Table 2 also shows the $\mathrm{S} / \mathrm{N}$ for each peak, which is defined as the ratio of the amplitude of the consensus spectrum at the peak $S_{i}\left(k_{\max }\right)$ and the mean value of $S_{i}(k)$ over the entire spectrum. Traditionally, this measure is used to determine the relevance of a frequency peak, but the $\mathrm{S} / \mathrm{N}$ obtained for each frequency peak does not correlate well with how often that frequency peak appears in the consensus spectrum of any group of protein sequences that belong to the family, and thus it cannot be considered a good measure of the significance of a frequency peak for that protein family.

In Tables A.1-A.6 included in Appendix A, we show the results obtained based on the detection of the main peaks in the remaining protein families that belong to the lysozyme clan (CL0037). According to the tables and the criterion established above, the different protein families have the following outstanding frequency peaks (two frequencies are considered the same when one is within the range \pm 20 of the other): PF00182 (at 301 and 332, which could be considered the same because they are very close), PF00959 (at 271 and 1091), PF01374 (at 187), PF01464 (at 337 and 1156), 


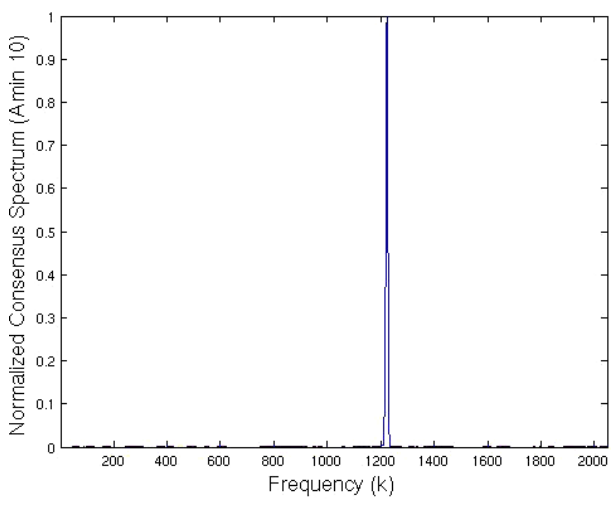

(a)

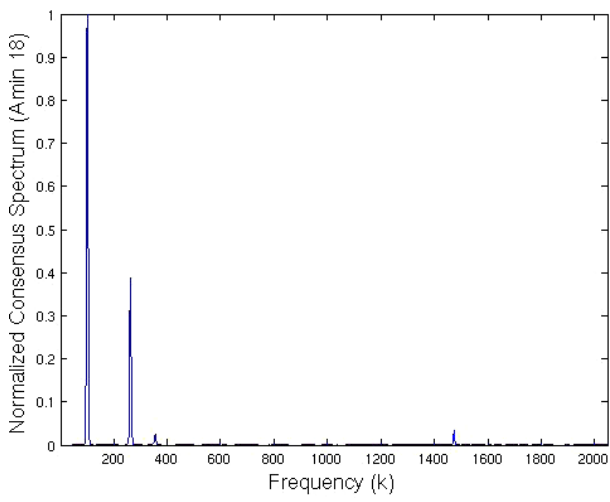

(b)

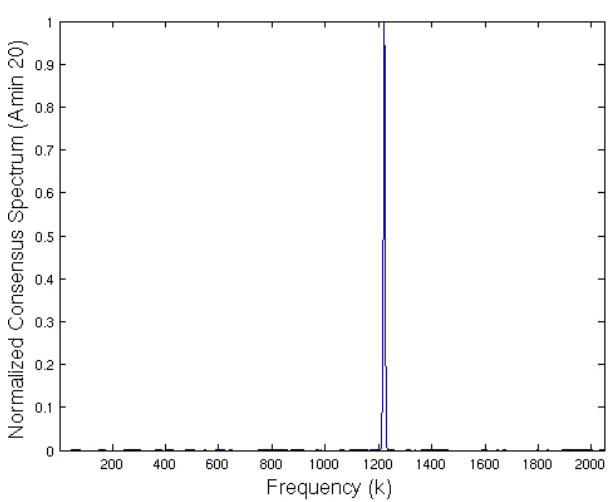

(c)

Fig. 3. Protein family PF00062. (a) Consensus spectrum of amino acid 10 (I). (b) Consensus spectrum of amino acid $18(\mathrm{~W})$. (c) Consensus spectrum of amino acid $20(\mathrm{~V})$.

PF01832 (at 181 and 1243), PF05838 (at 57, 970, 1140 and 1937), PF06737 (at 261, 1249, 1343, 1412 and 1481), PF06871 (at 679, 938, 1008, 1079 and 1157), PF10715 (at 686), PF13406 (at 163, 947 and 1206) and PF13702 (at 20, 61, 303, 808, 1046, 1185,1290 and 1947).

\section{Discussion}

\subsection{Comparison with the EIIP representation}

Traditionally, the consensus spectrum has been determined for the EIIP representation of protein sequences. In particular, it has been used to characterize several protein groups, ${ }^{14,44,53,56}$ including lysozymes. We were interested in studying whether for this EIIP representation a strong common periodicity also appears for a protein family, such as those strong common periodicities found in some of the amino acid signals of the proposed representation. According to Refs. 14 and 53 a strong 
peak appears around $f_{\max }=0.3264\left(k_{\max }=1337\right)$ with the EIIP representation, where they used the 15 sequences shown in Table 3 in the analysis.

Most of the sequences (11 sequences) used belong to the PF00062 family. We determined the consensus spectrum for these 11 sequences and obtained the maximum peak for $k_{\max }=1340$, which coincided $( \pm 20)$ with that of the complete 15 sequences, and we could check whether this is a major periodicity in the EIIP representation for the whole family PF00062. To achieve this, we determined the $k_{\max }$ of the consensus spectrum of the sequences belonging to the seed alignment for family PF00062 (21 sequences) using the EIIP representation, thereby finding that the maximum was at $k_{\max }=845$ (which did not agree with $k=1340$ ), but this maximum was not relevant according to the criterion developed in the previous section, as shown in Table 4 . For $k=1340$, we also checked how many of the 1000 random groups of 21 proteins agreed with this maximum, which showed that this only applied to 14 of the groups. Thus, we conclude that the EIIP representation is not a suitable representation for characterizing common regularities in an entire protein family, although it might be useful for characterizing certain features of some groups of proteins, as described in Ref. 44.

Thus, using our mathematical representation and based on the consensus spectrum of each of the 20 signals generated, we can obtain a characterization of the common periodicities of the protein sequences that belong to a protein family.

Table 3. List of lysozyme protein sequences used in Ref. 21.

\begin{tabular}{ll}
\hline PF00062 & Q06283, P61629, P61628, P00697, P00698, P00705 \\
& P00706, P00702, P00707, P00708, P00699 \\
PF01464 & P00718, P00719, P00717 \\
PF00959 & Q8SDG3 \\
\hline
\end{tabular}

\subsection{Profile $H M M s$}

We have shown how the proposed representation permits to detect common periodicities in the protein sequences belonging to a protein family. We are now

Table 4. Relevance determination for the consensus spectrum maximum peak with the PF00062 EIIP representation.

\begin{tabular}{lcc}
\hline & $k_{\max }$ & Count 1000 groups \\
21 seqs & 21 seqs each \\
PF00062 & SEED & FULL \\
\hline EIIP & 845 & 453 \\
\hline & & Count 1000 groups \\
& $k_{\max }$ & 21 seqs each \\
PF00062 & 11 seqs & FULL \\
\hline EIIP & 1340 & 14 \\
\hline
\end{tabular}


interested in studying the extent to which current PHMMs that model different protein families can reproduce the regularities detected using the proposed representation. We obtained the PHMMs available on Pfam (Release 27.0, March 2013) and used them to generate random amino acid sequences for each protein family according to the corresponding PHMM (with the MATLAB function hmmprofgenerate in the Bioinformatics toolbox). For each family, we generated the same number of sequences as the number of protein sequences in the full alignment of that family in Pfam and we then determined the consensus spectrum of the random amino acid sequences generated for each family, thereby obtaining $k_{\max }$ for each of the consensus spectra. To determine the relevance of the corresponding peak, we used the approach described in Sec. 3, i.e. 1000 groups of protein sequences were extracted randomly from the sequences in the full alignment of the protein family (the number of protein sequences in each group equalled the number of protein sequences in the seed alignment) and we then counted how many times the maximum of the consensus spectrum for each amino acid and for the 1000 groups agreed with that in the sequences generated by the PHMM $\left(k_{\max } \pm 20\right)$ for that amino acid. The results are shown in Tables 2 and A.1-A.6 for all of the protein families.

For the PF00062 family (Table 2), we can see that the corresponding PHMM reproduced the two main frequency peaks in the family, which corresponded to $k_{\max }=101 \pm 20$ and $k_{\max }=1221 \pm 20$. After analyzing the remaining protein families (Tables A.1-A.6), we found that the corresponding PHMMs also reproduced all of the main frequency peaks of the PF00182 and PF01832 families, as well as most (at least half) of the main frequency peaks of the PF00959, PF01464, PF05838, PF06737, PF13406 and PF13702 families. For the PF06871 family, only one of the main frequencies was reproduced whereas none of the significant frequency peaks were reproduced by the corresponding PHMM for the PF01374 and PF10715 families. The latter three cases are particularly interesting because they correspond to protein families with very few sequences available for the seed alignment what could affect the resulting PHMM.

\subsection{Integration into Chou's PseAAC}

The proposed representation based on the definition of a similarity measure generates 20 signals for each protein sequence that have been used to determine regularities in a protein family through the use of consensus spectra. These 20 signals could be used as well in other schemes of protein sequence representation such as in the very popular Chou's pseudo-amino acid composition (PseAAC) ${ }^{10}$ In Chou's PseAAC a protein chain $\mathbf{a}=[a(1), a(2), \ldots, a(L)]$ of $L$ amino acid residues is represented by a fixed length vector of $20+\lambda$ elements. The first 20 elements are the conventional amino acid composition $(\mathrm{AAC})^{40}[f(1), f(2), \ldots, f(20)]$ that is formed by 20 components, each reflecting the occurrence frequency in that protein of each one of the 20 essential amino acids. The additional $\lambda$ elements $[\theta(1), \theta(2), \ldots, \theta(\lambda)]$ 
reflect sequence order effects in the protein and are obtained $\operatorname{as}^{10}$

$$
\theta(\lambda)=\frac{1}{L-\lambda} \sum_{n=1}^{L-\lambda} \Theta(a(n), a(n+\lambda)) \quad 1 \leq \lambda, \lambda<L .
$$

$\Theta(a(n), a(m))$ is a correlation function given by

$$
\begin{aligned}
\Theta(a(n), a(m))= & \frac{1}{3}\left\{\left[h_{1}(a(m))-h_{1}(a(n))\right]^{2}+\left[h_{2}(a(m))-h_{2}(a(n))\right]^{2}\right. \\
& \left.+[m(a(m))-m(a(n))]^{2}\right\}
\end{aligned}
$$

where $h_{1}(a(n)), h_{2}(a(n))$ y $m(a(n))$ are, respectively, the hydrophobicity value, the hydrophilicity value and the side-chain mass of the corresponding amino acid. $\theta(\lambda)$ is called the $\lambda$-tier correlation factor and reflects the sequence order correlation between all the $\lambda$ most contiguous residues.

The final feature vector $\mathbf{v}=[v(1) \ldots v(20), v(20+1) \ldots v(20+\lambda)]$ is given by

$$
v(u)= \begin{cases}\frac{f(u)}{\sum_{i=1}^{20} f(i)+w \sum_{j=1}^{\lambda} \theta(j)} & 1 \leq u \leq 20, \\ \frac{w \theta(u-20)}{\sum_{i=1}^{20} f(i)+w \sum_{j=1}^{\lambda} \theta(j)} & 20+1 \leq u \leq 20+\lambda,\end{cases}
$$

where $w$ is a weight factor for the sequence order effect.

Chou also proposed another version of his PseAAC called amphiphilic pseudo amino acid composition (Am-PseAAC) ${ }^{11}$ where a protein chain is now represented by a fixed length vector of $20+2 \lambda$ elements. The first 20 elements are again the conventional AAC $[f(1), f(2), \ldots, f(20)]$ but, now, the $2 \lambda$ additional elements reflecting sequence order effects are given by ${ }^{11}$

$$
\begin{aligned}
\tau(2 \lambda-1) & =\frac{1}{L-\lambda} \sum_{n=1}^{L-\lambda} H_{1}(a(n), a(n+\lambda)) \quad 1 \leq \lambda, \quad \lambda<L, \\
\tau(2 \lambda) & =\frac{1}{L-\lambda} \sum_{n=1}^{L-\lambda} H_{2}(a(n), a(n+\lambda)) \quad 1 \leq \lambda, \quad \lambda<L,
\end{aligned}
$$

where $H_{1}(a(n), a(m))$ and $H_{2}(a(n), a(m))$ are the hydrophobicity and the hydrophilicity correlation functions given by

$$
\begin{aligned}
& H_{1}(a(n), a(m))=h_{1}(a(n)) h_{1}(a(m)), \\
& H_{2}(a(n), a(m))=h_{2}(a(n)) h_{2}(a(m)) .
\end{aligned}
$$

Since its introduction by Chou, the PseAAC has become rather popular, being applied in almost all areas of computational proteomics and, more recently, the idea has also been extended to DNA and RNA sequences (see the recent paper by Liu et $a l .{ }^{37}$ ). Although originally only some physicochemical properties of amino acids were 
used (hydrophobicity, hydrophilicity or side-chain mass), in fact any physicochemical properties, such as those listed in the amino acid index database, ${ }^{23}$ can be used.

Another possibility would be to use the proposed protein representation in 20 signals in the PseAAC. In the case of the first form of PseAAC (4) (also known as type I PseAAC) we would simply determine now the correlation function $\Theta(a(n), a$ $(m))$ as

$$
\Theta(a(n), a(m))=\frac{1}{20} \sum_{i=1}^{20}\left[x_{i}(m)-x_{i}(n)\right]^{2},
$$

where $x_{i}(n)$ is given by expression (2). The resulting vector would also have $20+\lambda$ elements. In the case of the second form of PseAAC (7) (also known as type II PseAAC) we would now have 20 correlation functions $H_{i}(a(n), a(m))$ given by

$$
H_{i}(a(n), a(m))=x_{i}(n) x_{i}(m) \quad i=1, \ldots, 20 .
$$

In this case, the resulting vector would have $20+20 \lambda$ elements.

Chou's PseAAC has been used for a wide variety of applications. ${ }^{37}$ In order to compare the PseAAC based on physicochemical properties of amino acids with that one based on the proposed representation in 20 signals we will use it for the same task described in Ref. 11. In Ref. 11 the PseAAC was used to predict enzyme subfamily classes (with average sequence identity percentages within the range of 11-27\%). There are 16 subfamily classes in the dataset and the Am-PseAAC was used for the classification task. In our case we will carry out the same task but with the type I PseAAC, both using physicochemical properties of amino acids and the proposed representation in 20 signals and compare with the results in Ref. 11. The representations described in Table 5 will be used.

PseAACIIorg is the amphiphilic representation (type II PseAAC) proposed in Ref. 11 where two physicochemical properties are used (hydrophobicity and hydrophilicity) and PseAACIorg is the type I PseAAC representation proposed in Ref. 10 where three physicochemical properties are used (hydrophobicity, hydrophilicity and side-chain mass). PseAACI12 and PseAACIall are also type I PseAAC representations where the only difference with respect to PseAACIorg lies in the number and type of the physicochemical properties considered. PseAACI12 uses the 12 major physicochemical properties of amino acids listed in Ref. 47 and PseAACIall considers all the physicochemical properties included in the amino acid index

Table 5. Pseudo amino acid representations.

\begin{tabular}{lcccc}
\hline Name & Type & Properties & $\lambda$ & $w$ \\
\hline PseAACIIorg & type II PseAAC & Two physicochemical prop. ${ }^{11}$ & 9 & 0.5 \\
PseAACIorg & type I PseAAC & Three physicochemical prop. & 9 & 0.05 \\
PseAACI12 & type I PseAAC $^{10}$ & 12 physicochemical prop. & 9 & 0.05 \\
PseAACIall & type I PseAAC & All physicochemical prop. ${ }^{23}$ & 9 & 0.05 \\
PseAACI20 & type I PseAAC & Proposed 20 signals equation (9) $^{13}$ & 9 & 0.05 \\
\hline
\end{tabular}


database $^{23}$ (531 properties, although there are 544 in the database some of them do not assign values to all the amino acids). Finally, PseAACI20 is also a type I PseAAC representation where, instead of considering physicochemical properties, the 20 signals derived from the proposed similarity measure are used (9).

As mentioned before, PseAACIIorg is the type of representation proposed in Ref. 11 where the values $\lambda=9$ and $w=0.5$ were used. We have then used the same value of $\lambda$ for the rest of the representations in order to have a fair comparison among them, since $\lambda$ is the highest correlation order that is considered in a representation. The reason for fixing a value of 0.05 for parameter $w$ in the case of the type I PseAAC representations is that it is the value used in Ref. 10 and the most frequently used value for this type of representation.

In order to compare with the results obtained in Ref. 11 we are going to apply the same type of classifier used in that paper, that is, the covariant discriminant algorithm. The results obtained with the five representations listed in Table 5 and with the task mentioned above are shown in Table 6. In the case of the type II PseAAC only the two original physicochemical properties proposed in Ref. 11 have been used as the results degrade when more physicochemical properties are introduced in this representation. The test method used is the jackknife test which is the most rigorous and objective in reflecting the real power of a predictor as indicated in Ref. 11.

The results show that the proposed protein representation in 20 signals can be successfully incorporated in other protein representation schemes such as Chou's PseAAC. As we can observe, the best results are obtained with the proposed representation that gets even better results than using the 531 amino acid indices and with a much lower computational complexity (in Eq. (5) we would have a summation

Table 6. Success rates for the classification task with the different PseAAC representations.

\begin{tabular}{cccccc}
\hline $\begin{array}{c}\text { Subfamily } \\
\text { class }\end{array}$ & $\begin{array}{c}\text { PseAACIIorg } \\
(\%)\end{array}$ & $\begin{array}{c}\text { PseAACIorg } \\
(\%)\end{array}$ & $\begin{array}{c}\text { PseAACI12 } \\
(\%)\end{array}$ & $\begin{array}{c}\text { PseAACIall } \\
(\%)\end{array}$ & $\begin{array}{c}\text { PseAACI20 } \\
(\%)\end{array}$ \\
\hline 1 & 76.09 & 66.33 & 70.37 & 69.70 & 71.38 \\
2 & 64.18 & 61.69 & 58.71 & 62.19 & 61.69 \\
3 & 65.00 & 57.22 & 58.89 & 65.56 & 68.33 \\
4 & 59.02 & 57.38 & 59.84 & 60.66 & 58.20 \\
5 & 50.48 & 50.48 & 52.38 & 52.38 & 57.14 \\
6 & 78.60 & 77.54 & 76.84 & 76.49 & 75.79 \\
7 & 37.70 & 40.98 & 34.43 & 37.70 & 39.34 \\
8 & 21.43 & 32.14 & 42.86 & 41.07 & 42.86 \\
9 & 82.66 & 87.10 & 87.50 & 87.10 & 87.90 \\
10 & 64.89 & 70.21 & 70.21 & 69.14 & 69.15 \\
11 & 82.55 & 82.55 & 83.89 & 84.56 & 86.58 \\
12 & 47.78 & 54.44 & 53.33 & 56.67 & 51.11 \\
13 & 80.00 & 78.04 & 78.82 & 78.82 & 80.78 \\
14 & 95.14 & 93.06 & 95.83 & 95.83 & 96.53 \\
15 & 56.10 & 65.85 & 68.29 & 69.51 & 67.07 \\
16 & 72.03 & 71.33 & 75.52 & 79.02 & 79.02 \\
Overall & $\mathbf{7 0 . 7 5}$ & $\mathbf{6 9 . 8 0}$ & $\mathbf{7 0 . 9 9}$ & $\mathbf{7 2 . 0 2}$ & $\mathbf{7 2 . 6 2}$ \\
\hline
\end{tabular}


of just 20 terms instead of 531 terms). In the recent paper by Liu et al. ${ }^{37}$ a new web server (Pse-in-One) is presented where, in addition to the physicochemical properties included in the amino acid index database, user-defined properties are also permited, facilitating the use of the proposed representation or others to the scientific community.

\section{Conclusion}

In this study, we proposed a mathematical representation of the amino acid chain that comprises a protein using a similarity measure based on the PAM250 amino acid substitution matrix. This representation generates 20 signals for each protein sequence and with this representation a protein family is characterized by a group of significant frequency peaks, which represent the common periodicities in the amino acid sequences that belong to the protein family. We applied our representation method to the 12 families of the lysozyme clan (CL0037) in Pfam (Release 27.0, March 2013). We also compared our approach with the EIIP method, which employs an amino acid index as a numerical representation of the sequence, but the EIIP could not identify the regularities that we detected in a family using our approach. Furthermore, we investigated the extent to which current PHMMs used to model each family can reproduce the main peaks in each family, which showed that the corresponding PHMMs could reproduce all or many of the main frequencies in most of the families, with the exception of families with a very low number of seed sequences. These results suggest that the proposed representation could be used for the analysis of PHMM structures or for their improvement (particularly when a low number of seed sequences is available), as well as explored its relationship with protein structure or active site location. Finally, the new representation in 20 signals was shown to be a useful alternative to amino acid physicochemical properties in Chou's PseAAC.

Since user-friendly and publicly available web-servers not only represent the future direction for developing more useful models, simulated methods, or predictors, but also significantly enhance their impacts, as demonstrated in a series of recent publications, ${ }^{2,13,17,22,25,34,52,57}$ we shall make efforts in our future work to provide a web-server for the methods presented in this paper.

\section{Acknowledgments}

This research was supported by Project P12.TIC.1485 funded by Consejeria de Economia, Innovacion y Ciencia (Junta de Andalucia). 
V. Sanchez et al.

\section{Appendix A}

Table A.1. Characterization of protein families PF00182 and PF00959.

\begin{tabular}{|c|c|c|c|c|c|c|c|c|}
\hline \multirow{3}{*}{$\begin{array}{l}\text { Amino } \\
\text { acid }\end{array}$} & \multicolumn{4}{|c|}{ PF00182 } & \multicolumn{4}{|c|}{ PF00959 } \\
\hline & $\begin{array}{c}k_{\max } \\
17 \\
\text { seqs }\end{array}$ & $\begin{array}{l}\text { Count } 1000 \\
\text { groups } \\
17 \text { seqs } \\
\text { each }\end{array}$ & $\begin{array}{c}k_{\max } \\
2014 \\
\text { seqs }\end{array}$ & $\begin{array}{c}\text { Count } 1000 \\
\text { groups } \\
17 \text { seqs } \\
\text { each }\end{array}$ & $\begin{array}{c}k_{\max } \\
18 \\
\text { seqs }\end{array}$ & $\begin{array}{l}\text { Count } 1000 \\
\text { groups } \\
18 \text { seqs } \\
\text { each }\end{array}$ & $\begin{array}{l}k_{\max } \\
3255 \\
\text { seqs }\end{array}$ & $\begin{array}{c}\text { Count } 1000 \\
\text { groups } \\
18 \text { seqs } \\
\text { each }\end{array}$ \\
\hline & SEED & FULL & PHMM & FULL & SEED & FULL & PHMM & FULL \\
\hline A, 1 & 300 & 16 & 63 & 0 & 1885 & 12 & 275 & 105 \\
\hline $\mathrm{R}, 2$ & 82 & 5 & 341 & 209 & 1080 & 763 & 140 & 0 \\
\hline $\mathrm{N}, 3$ & 1915 & 492 & 107 & 5 & 1049 & 7 & 139 & 0 \\
\hline $\mathrm{D}, 4$ & 1915 & 442 & 130 & 197 & 1049 & 1 & 285 & 227 \\
\hline $\mathrm{C}, 5$ & 655 & 246 & 656 & 246 & 756 & 3 & 260 & 2 \\
\hline $\mathrm{Q}, 6$ & 1045 & 165 & 105 & 50 & 1255 & 1 & 138 & 198 \\
\hline $\mathrm{E}, 7$ & 1046 & 29 & 106 & 273 & 1962 & 9 & 138 & 1 \\
\hline $\mathrm{G}, 8$ & 1612 & 91 & 60 & 30 & 527 & 92 & 276 & 696 \\
\hline $\mathrm{H}, 9$ & 83 & 17 & 717 & 8 & 1829 & 5 & 135 & 11 \\
\hline $\mathrm{I}, 10$ & 715 & 20 & 151 & 181 & 453 & 0 & 290 & 341 \\
\hline $\mathrm{L}, 11$ & 878 & 20 & 151 & 75 & 1046 & 0 & 284 & 929 \\
\hline $\mathrm{K}, 12$ & 889 & 13 & 104 & 0 & 1091 & 860 & 139 & 26 \\
\hline M, 13 & 879 & 7 & 151 & 3 & 271 & 745 & 289 & 753 \\
\hline $\mathrm{F}, 14$ & 257 & 413 & 133 & 59 & 1144 & 8 & 281 & 3 \\
\hline $\mathrm{P}, 15$ & 332 & 598 & 332 & 598 & 1090 & 197 & 137 & 5 \\
\hline S, 16 & 530 & 115 & 175 & 15 & 1048 & 1 & 281 & 273 \\
\hline $\mathrm{T}, 17$ & 38 & 10 & 251 & 122 & 1047 & 0 & 532 & 49 \\
\hline $\mathrm{W}, 18$ & 226 & 111 & 223 & 110 & 639 & 3 & 508 & 25 \\
\hline $\mathrm{Y}, 19$ & 301 & 662 & 299 & 662 & 887 & 13 & 282 & 0 \\
\hline $\mathrm{V}, 20$ & 717 & 140 & 151 & 28 & 1694 & 2 & 291 & 104 \\
\hline
\end{tabular}

Table A.2. Characterization of protein families PF01374 and PF01464.

\begin{tabular}{|c|c|c|c|c|c|c|c|c|}
\hline \multirow[b]{2}{*}{$\begin{array}{l}\text { Amino } \\
\text { acid }\end{array}$} & \multicolumn{4}{|c|}{ PF01374 } & \multicolumn{4}{|c|}{ PF01464 } \\
\hline & $\begin{array}{c}k_{\max } \\
7 \\
\text { seqs } \\
\text { SEED }\end{array}$ & $\begin{array}{c}\text { Count } 1000 \\
\text { groups } \\
7 \text { seqs } \\
\text { each } \\
\text { FULL }\end{array}$ & $\begin{array}{c}k_{\max } \\
127 \\
\text { seqs } \\
\text { PHMM }\end{array}$ & $\begin{array}{c}\text { Count } 1000 \\
\text { groups } \\
7 \text { seqs } \\
\text { each } \\
\text { FULL }\end{array}$ & $\begin{array}{c}k_{\max } \\
39 \\
\text { seqs } \\
\text { SEED }\end{array}$ & $\begin{array}{c}\text { Count } 1000 \\
\text { groups } \\
39 \text { seqs } \\
\text { each } \\
\text { FULL }\end{array}$ & $\begin{array}{c}k_{\max } \\
14235 \\
\text { seqs } \\
\text { PHMM }\end{array}$ & $\begin{array}{c}\text { Count } 1000 \\
\text { groups } \\
39 \text { seqs } \\
\text { each } \\
\text { FULL }\end{array}$ \\
\hline $\mathrm{A}, 1$ & 1973 & 184 & 1667 & 0 & 621 & 90 & 624 & 89 \\
\hline $\mathrm{R}, 2$ & 1363 & 144 & 240 & 14 & 171 & 181 & 156 & 165 \\
\hline $\mathrm{N}, 3$ & 189 & 718 & 268 & 103 & 1156 & 696 & 319 & 87 \\
\hline $\mathrm{D}, 4$ & 272 & 88 & 1169 & 118 & 1156 & 303 & 316 & 26 \\
\hline C, 5 & 1056 & 113 & 748 & 0 & 1933 & 100 & 1363 & 2 \\
\hline $\mathrm{Q}, 6$ & 176 & 140 & 38 & 156 & 1151 & 260 & 1145 & 161 \\
\hline $\mathrm{E}, 7$ & 176 & 470 & 1172 & 141 & 1151 & 210 & 314 & 2 \\
\hline $\mathrm{G}, 8$ & 75 & 31 & 75 & 31 & 617 & 235 & 275 & 137 \\
\hline $\mathrm{H}, 9$ & 1609 & 15 & 1788 & 2 & 1698 & 36 & 152 & 70 \\
\hline $\mathrm{I}, 10$ & 1231 & 493 & 1413 & 13 & 1149 & 242 & 272 & 1 \\
\hline $\mathrm{L}, 11$ & 1236 & 79 & 1230 & 80 & 337 & 848 & 323 & 842 \\
\hline
\end{tabular}


Table A.2. (Continued)

\begin{tabular}{|c|c|c|c|c|c|c|c|c|}
\hline \multirow[b]{2}{*}{$\begin{array}{l}\text { Amino } \\
\text { acid }\end{array}$} & \multicolumn{4}{|c|}{ PF01374 } & \multicolumn{4}{|c|}{ PF01464 } \\
\hline & $\begin{array}{c}k_{\max } \\
7 \\
\text { seqs } \\
\text { SEED }\end{array}$ & $\begin{array}{c}\text { Count } 1000 \\
\text { groups } \\
7 \text { seqs } \\
\text { each } \\
\text { FULL }\end{array}$ & $\begin{array}{c}k_{\max } \\
127 \\
\text { seqs } \\
\text { PHMM }\end{array}$ & $\begin{array}{c}\text { Count } 1000 \\
\text { groups } \\
7 \text { seqs } \\
\text { each } \\
\text { FULL }\end{array}$ & $\begin{array}{c}k_{\max } \\
39 \\
\text { seqs } \\
\text { SEED }\end{array}$ & $\begin{array}{c}\text { Count } 1000 \\
\text { groups } \\
39 \text { seqs } \\
\text { each } \\
\text { FULL }\end{array}$ & $\begin{array}{c}k_{\max } \\
14235 \\
\text { seqs } \\
\text { PHMM }\end{array}$ & $\begin{array}{c}\text { Count } 1000 \\
\text { groups } \\
39 \text { seqs } \\
\text { each } \\
\text { FULL }\end{array}$ \\
\hline $\mathrm{K}, 12$ & 1361 & 112 & 39 & 120 & 1150 & 402 & 156 & 225 \\
\hline M, 13 & 159 & 2 & 53 & 9 & 331 & 640 & 124 & 147 \\
\hline $\mathrm{F}, 14$ & 267 & 336 & 238 & 0 & 1009 & 258 & 1647 & 17 \\
\hline $\mathrm{P}, 15$ & 484 & 72 & 1334 & 42 & 1606 & 70 & 1031 & 187 \\
\hline S, 16 & 187 & 833 & 268 & 34 & 1154 & 148 & 322 & 356 \\
\hline $\mathrm{T}, 17$ & 977 & 222 & 1349 & 5 & 337 & 248 & 319 & 179 \\
\hline $\mathrm{W}, 18$ & 48 & 80 & 265 & 2 & 1217 & 46 & 1639 & 66 \\
\hline $\mathrm{Y}, 19$ & 1613 & 12 & 55 & 1 & 1287 & 20 & 35 & 1 \\
\hline $\mathrm{V}, 20$ & 1231 & 198 & 185 & 91 & 1152 & 72 & 155 & 2 \\
\hline
\end{tabular}

Table A.3. Characterization of protein families PF01832 and PF05838.

\begin{tabular}{|c|c|c|c|c|c|c|c|c|}
\hline \multirow[b]{2}{*}{$\begin{array}{l}\text { Amino } \\
\text { acid }\end{array}$} & \multicolumn{4}{|c|}{ PF01832 } & \multicolumn{4}{|c|}{ PF05838 } \\
\hline & $\begin{array}{c}k_{\max } \\
162 \\
\text { seqs } \\
\text { SEED }\end{array}$ & $\begin{array}{c}\text { Count } 1000 \\
\text { groups } \\
162 \text { seqs } \\
\text { each } \\
\text { FULL }\end{array}$ & $\begin{array}{c}k_{\max } \\
6435 \\
\text { seqs } \\
\text { PHMM }\end{array}$ & $\begin{array}{c}\text { Count } 1000 \\
\text { groups } \\
162 \text { seqs } \\
\text { each } \\
\text { FULL }\end{array}$ & $\begin{array}{c}k_{\max } \\
20 \\
\text { seqs } \\
\text { SEED }\end{array}$ & $\begin{array}{l}\text { Count } 1000 \\
\text { groups } \\
20 \text { seqs } \\
\text { each } \\
\text { FULL }\end{array}$ & $\begin{array}{c}k_{\max } \\
820 \\
\text { seqs } \\
\text { PHMM }\end{array}$ & $\begin{array}{c}\text { Count } 1000 \\
\text { groups } \\
20 \text { seqs } \\
\text { each } \\
\text { FULL }\end{array}$ \\
\hline $\mathrm{A}, 1$ & 1181 & 183 & 1204 & 105 & 1937 & 721 & 61 & 6 \\
\hline $\mathrm{R}, 2$ & 195 & 227 & 1263 & 96 & 970 & 892 & 957 & 879 \\
\hline $\mathrm{N}, 3$ & 709 & 382 & 1204 & 0 & 974 & 72 & 960 & 16 \\
\hline $\mathrm{D}, 4$ & 708 & 3 & 1202 & 0 & 979 & 503 & 967 & 248 \\
\hline $\mathrm{C}, 5$ & 869 & 188 & 1364 & 0 & 1125 & 165 & 1167 & 2 \\
\hline $\mathrm{Q}, 6$ & 1094 & 458 & 1179 & 0 & 956 & 192 & 950 & 177 \\
\hline $\mathrm{E}, 7$ & 754 & 100 & 1204 & 0 & 974 & 540 & 965 & 457 \\
\hline $\mathrm{G}, 8$ & 1919 & 130 & 1202 & 2 & 57 & 599 & 57 & 599 \\
\hline $\mathrm{H}, 9$ & 1358 & 301 & 723 & 213 & 1019 & 96 & 957 & 26 \\
\hline $\mathrm{I}, 10$ & 181 & 621 & 189 & 621 & 953 & 747 & 171 & 5 \\
\hline $\mathrm{L}, 11$ & 1240 & 185 & 1205 & 6 & 1492 & 398 & 963 & 187 \\
\hline $\mathrm{K}, 12$ & 1263 & 412 & 1197 & 53 & 966 & 560 & 942 & 397 \\
\hline M, 13 & 178 & 501 & 185 & 501 & 1140 & 816 & 108 & 2 \\
\hline $\mathrm{F}, 14$ & 1251 & 409 & 1231 & 785 & 960 & 8 & 178 & 23 \\
\hline $\mathrm{P}, 15$ & 1029 & 1 & 1180 & 1 & 159 & 93 & 162 & 93 \\
\hline $\mathrm{S}, 16$ & 1243 & 652 & 1205 & 263 & 57 & 62 & 56 & 62 \\
\hline $\mathrm{T}, 17$ & 1252 & 246 & 1234 & 291 & 877 & 56 & 167 & 61 \\
\hline $\mathrm{W}, 18$ & 992 & 4 & 1640 & 0 & 116 & 278 & 145 & 95 \\
\hline $\mathrm{Y}, 19$ & 1172 & 125 & 1232 & 153 & 191 & 239 & 183 & 246 \\
\hline $\mathrm{V}, 20$ & 181 & 408 & 187 & 408 & 961 & 775 & 173 & 1 \\
\hline
\end{tabular}


Table A.4. Characterization of protein families PF06737 and PF06871.

\begin{tabular}{|c|c|c|c|c|c|c|c|c|}
\hline \multirow[b]{2}{*}{$\begin{array}{l}\text { Amino } \\
\text { acid }\end{array}$} & \multicolumn{4}{|c|}{ PF06737 } & \multicolumn{4}{|c|}{ PF06871 } \\
\hline & $\begin{array}{c}k_{\max } \\
18 \\
\text { seqs } \\
\text { SEED }\end{array}$ & $\begin{array}{c}\text { Count } 1000 \\
\text { groups } \\
18 \text { seqs } \\
\text { each } \\
\text { FULL }\end{array}$ & $\begin{array}{c}k_{\max } \\
1273 \\
\text { seqs } \\
\text { PHMM }\end{array}$ & $\begin{array}{l}\text { Count } 1000 \\
\text { groups } \\
18 \text { seqs } \\
\text { each } \\
\text { FULL }\end{array}$ & $\begin{array}{c}k_{\max } \\
8 \\
\text { seqs } \\
\text { SEED }\end{array}$ & $\begin{array}{c}\text { Count } 1000 \\
\text { groups } \\
8 \text { seqs } \\
\text { each } \\
\text { FULL }\end{array}$ & $\begin{array}{c}k_{\max } \\
33 \\
\text { seqs } \\
\text { PHMM }\end{array}$ & $\begin{array}{c}\text { Count } 1000 \\
\text { groups } \\
8 \text { seqs } \\
\text { each } \\
\text { FULL }\end{array}$ \\
\hline A, 1 & 1481 & 817 & 1487 & 819 & 1786 & 203 & 676 & 636 \\
\hline $\mathrm{R}, 2$ & 1249 & 554 & 1455 & 1 & 1079 & 982 & 937 & 1 \\
\hline $\mathrm{N}, 3$ & 1413 & 218 & 1421 & 218 & 1008 & 1000 & 18 & 0 \\
\hline $\mathrm{D}, 4$ & 1342 & 956 & 1352 & 956 & 1007 & 982 & 19 & 2 \\
\hline $\mathrm{C}, 5$ & 261 & 717 & 315 & 135 & 1157 & 941 & 193 & 0 \\
\hline $\mathrm{Q}, 6$ & 1420 & 652 & 1409 & 634 & 929 & 102 & 19 & 0 \\
\hline $\mathrm{E}, 7$ & 1343 & 988 & 1351 & 988 & 1008 & 967 & 19 & 3 \\
\hline $\mathrm{G}, 8$ & 619 & 113 & 300 & 823 & 327 & 423 & 319 & 423 \\
\hline $\mathrm{H}, 9$ & 2038 & 2 & 1750 & 7 & 938 & 271 & 19 & 0 \\
\hline $\mathrm{I}, 10$ & 1938 & 606 & 2027 & 1 & 938 & 558 & 18 & 0 \\
\hline $\mathrm{L}, 11$ & 1927 & 236 & 370 & 28 & 1874 & 152 & 18 & 0 \\
\hline $\mathrm{K}, 12$ & 1412 & 916 & 1035 & 0 & 926 & 5 & 62 & 0 \\
\hline M, 13 & 1934 & 341 & 381 & 42 & 1782 & 207 & 18 & 3 \\
\hline $\mathrm{F}, 14$ & 78 & 468 & 621 & 294 & 690 & 668 & 30 & 0 \\
\hline $\mathrm{P}, 15$ & 1640 & 219 & 625 & 425 & 971 & 342 & 116 & 154 \\
\hline $\mathrm{S}, 16$ & 1480 & 568 & 625 & 381 & 679 & 1000 & 230 & 0 \\
\hline $\mathrm{T}, 17$ & 1491 & 504 & 1488 & 682 & 795 & 381 & 31 & 0 \\
\hline $\mathrm{W}, 18$ & 1338 & 961 & 118 & 0 & 782 & 374 & 25 & 343 \\
\hline $\mathrm{Y}, 19$ & 618 & 257 & 619 & 254 & 689 & 607 & 27 & 149 \\
\hline $\mathrm{V}, 20$ & 1938 & 440 & 2028 & 1 & 1880 & 246 & 18 & 1 \\
\hline
\end{tabular}

Table A.5. Characterization of protein families PF10715 and PF13406.

\begin{tabular}{|c|c|c|c|c|c|c|c|c|}
\hline \multirow[b]{2}{*}{$\begin{array}{l}\text { Amino } \\
\text { acid }\end{array}$} & \multicolumn{4}{|c|}{ PF10715 } & \multicolumn{4}{|c|}{ PF13406 } \\
\hline & $\begin{array}{c}k_{\max } \\
14 \\
\text { seqs } \\
\text { SEED }\end{array}$ & $\begin{array}{c}\text { Count } 1000 \\
\text { groups } \\
14 \text { seqs } \\
\text { each } \\
\text { FULL }\end{array}$ & $\begin{array}{c}k_{\max } \\
136 \\
\text { seqs } \\
\text { PHMM }\end{array}$ & $\begin{array}{l}\text { Count } 1000 \\
\text { groups } \\
14 \text { seqs } \\
\text { each } \\
\text { FULL }\end{array}$ & $\begin{array}{c}k_{\max } \\
176 \\
\text { seqs } \\
\text { SEED }\end{array}$ & $\begin{array}{c}\text { Count } 1000 \\
\text { groups } \\
176 \text { seqs } \\
\text { each } \\
\text { FULL }\end{array}$ & $\begin{array}{c}k_{\max } \\
3080 \\
\text { seqs } \\
\text { PHMM }\end{array}$ & $\begin{array}{c}\text { Count } 1000 \\
\text { groups } \\
176 \text { seqs } \\
\text { each } \\
\text { FULL }\end{array}$ \\
\hline $\mathrm{A}, 1$ & 636 & 444 & 1480 & 17 & 1206 & 17 & 105 & 0 \\
\hline $\mathrm{R}, 2$ & 1670 & 12 & 1773 & 2 & 212 & 278 & 54 & 0 \\
\hline $\mathrm{N}, 3$ & 1086 & 310 & 1153 & 0 & 1206 & 953 & 1213 & 953 \\
\hline $\mathrm{D}, 4$ & 626 & 132 & 1065 & 35 & 948 & 34 & 1219 & 77 \\
\hline $\mathrm{C}, 5$ & 95 & 28 & 763 & 2 & 1011 & 15 & 1639 & 41 \\
\hline $\mathrm{Q}, 6$ & 1007 & 141 & 612 & 13 & 427 & 428 & 1211 & 3 \\
\hline $\mathrm{E}, 7$ & 626 & 150 & 410 & 23 & 947 & 909 & 1220 & 1 \\
\hline $\mathrm{G}, 8$ & 686 & 705 & 265 & 28 & 1204 & 272 & 1212 & 272 \\
\hline $\mathrm{H}, 9$ & 153 & 203 & 1474 & 1 & 427 & 256 & 220 & 0 \\
\hline $\mathrm{I}, 10$ & 1012 & 396 & 1233 & 0 & 161 & 836 & 160 & 836 \\
\hline $\mathrm{L}, 11$ & 985 & 66 & 1186 & 43 & 1206 & 953 & 1209 & 953 \\
\hline $\mathrm{K}, 12$ & 211 & 105 & 1950 & 42 & 1205 & 221 & 49 & 0 \\
\hline M, 13 & 246 & 232 & 1073 & 4 & 1446 & 259 & 160 & 119 \\
\hline
\end{tabular}


Table A.5. (Continued)

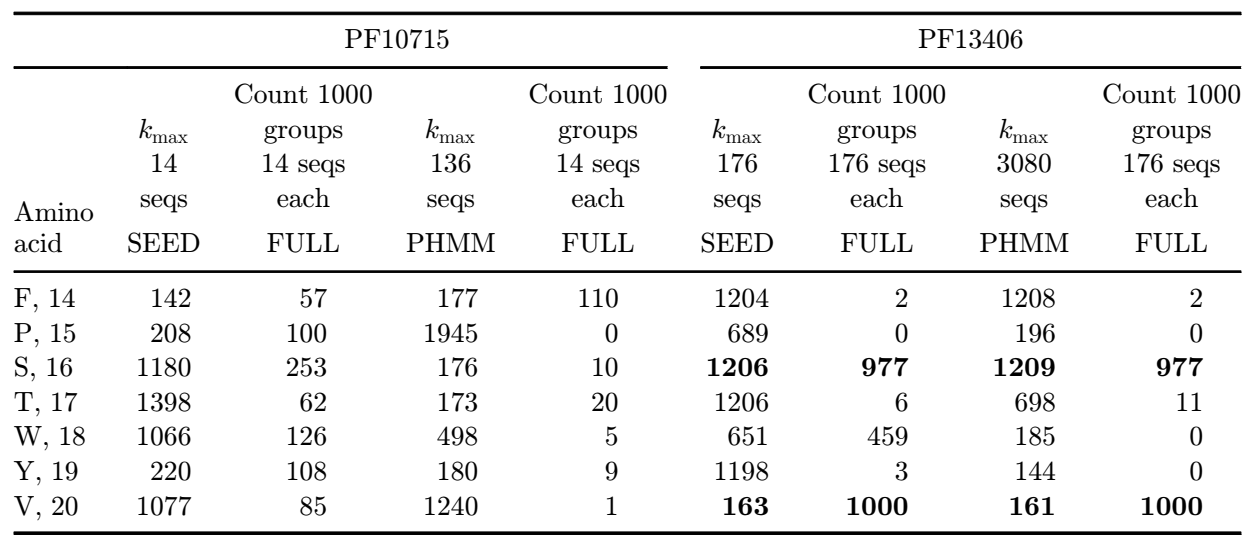

Table A.6. Characterization of protein family PF13702.

\begin{tabular}{lrrrr}
\hline & \multicolumn{3}{c}{ PF13702 } \\
\hline & \multicolumn{1}{c}{$k_{\text {max }}$} & Count 1000 groups & $k_{\max }$ & Count 1000 groups \\
Amino & 14 seqs & 14 seqs each & 136 seqs & 14 seqs each \\
acid & SEED & FULL & PHMM & FULL \\
\hline A, 1 & $\mathbf{1 9 4 7}$ & $\mathbf{7 8 5}$ & $\mathbf{1 9 4 9}$ & $\mathbf{7 8 5}$ \\
R, 2 & 208 & 0 & 1049 & 105 \\
N, 3 & $\mathbf{1 2 9 0}$ & $\mathbf{6 4 7}$ & 191 & 277 \\
D, 4 & $\mathbf{1 2 8 1}$ & $\mathbf{6 1 8}$ & 191 & 325 \\
C, 5 & $\mathbf{4 5}$ & $\mathbf{7 7 3}$ & 1697 & 2 \\
Q, 6 & 1043 & 442 & 1164 & 0 \\
E, 7 & 1280 & 166 & 1174 & 10 \\
G, 8 & 299 & 24 & 276 & 24 \\
H, 9 & $\mathbf{8 0 8}$ & $\mathbf{9 9 8}$ & 1116 & 0 \\
I, 10 & $\mathbf{1 1 8 5}$ & $\mathbf{9 9 8}$ & $\mathbf{1 1 6 9}$ & $\mathbf{9 9 8}$ \\
L, 11 & $\mathbf{3 0 3}$ & $\mathbf{8 1 1}$ & 279 & 54 \\
K, 12 & $\mathbf{1 0 4 6}$ & $\mathbf{9 8 1}$ & 69 & 13 \\
M, 13 & 779 & 413 & 282 & 0 \\
F, 14 & $\mathbf{2 0}$ & $\mathbf{9 8 5}$ & 175 & 0 \\
P, 15 & 59 & 128 & 57 & 128 \\
S, 16 & $\mathbf{6 1}$ & $\mathbf{9 8 9}$ & $\mathbf{5 6}$ & $\mathbf{9 8 9}$ \\
T, 17 & $\mathbf{6 4}$ & $\mathbf{5 7 3}$ & 1941 & 419 \\
W, 18 & 1576 & 1 & 483 & 33 \\
Y, 19 & $\mathbf{2 0}$ & $\mathbf{9 8 8}$ & $\mathbf{2 4}$ & $\mathbf{9 8 8}$ \\
W, 20 & 1272 & 1 & $\mathbf{9 9 6}$ \\
\hline & & & & \\
\hline
\end{tabular}

\section{References}

1. Chen C, Shen ZB, Zou XY, Dual-layer wavelet SVM for predicting protein structural class via the general Form of Chou's pseudo amino acid composition, Protein Peptide Lett 19:422-429, 2012. 
2. Chen W, Feng PM, Deng EZ, iTIS-PseTNC: A sequence-based predictor for identifying translation initiation site in human genes using pseudo trinucleotide composition, Anal Biochem 462:76-83, 2014.

3. Chen W, Feng PM, Lin H, iSS-PseDNC: Identifying splicing sites using pseudo dinucleotide composition, BioMed Res Int 2014:623149.

4. Chen W, Lei TY, Jin DC, PseKNC: A flexible web-server for generating pseudo K-tuple nucleotide composition, Anal Biochem 456:53-60, 2014.

5. Chen W, Zhang X, Brooker J, PseKNC-General: A cross-platform package for generating various modes of pseudo nucleotide compositions, Bioinformatics 31:119-120, 2015.

6. Chen W, Lin H, Pseudo nucleotide composition or PseKNC: An effective formulation for analyzing genomic sequences, Mol BioSys 2015, doi:10.1039/c5mb00155b.

7. Chou KC, The biological functions of low-frequency phonons. 4. Resonance effects and allosteric transition, Biophys Chem 20:61-71, 1984.

8. Chou KC, Review: Low-frequency collective motion in biomacromolecules and its biological functions, Biophys Chem 30:3-48, 1988.

9. Chou KC, Low-frequency resonance and cooperativity of hemoglobin, Trends Biochem Sci 14:212-213, 1989.

10. Chou KC, Prediction of protein cellular attributes using pseudo-amino-acid-composition, Proteins 43:246-255, 2001.

11. Chou KC, Using amphiphilic pseudo amino acid composition to predict enzyme subfamily classes, Bioinformatics 21:10-19, 2005.

12. Chou KC, Some remarks on protein attribute prediction and pseudo amino acid composition, (50th Anniversary Year Review), J Theor Biol 273:236-247, 2011.

13. Chou KC, Impacts of bioinformatics to medicinal chemistry, Med Chem 11:218-234, 2015.

14. Cosic I, Macromolecular bioactivity: Is it resonant interaction between macromolecules?theory and applications, IEEE Trans. Biomed. Eng. 41:1101-1114, 1994.

15. Cosic I, The Resonant Recognition Model of Macromolecular Bioactivity, Birkhauser Verlag, Basel, Switzerland, 1997.

16. Dayhoff MO, Schwartz RM, Orcutt BC, A model of evolutionary change in proteins, Atlas Protein Sequences Struct 5:345-352, 1978.

17. Ding H, Deng EZ, Yuan LF, Liu L, iCTX-Type: A sequence-based predictor for identifying the types of conotoxins in targeting ion channels, BioMed Res Int 2014:286419, 2014.

18. Du P, Wang X, Xu C, Gao Y, PseAAC-Builder: A cross-platform stand-alone program for generating various special Chou's pseudo-amino acid compositions, Analy Biochem 425:117-119, 2012.

19. Du P, Gu S, Jiao Y, PseAAC-General: Fast building various modes of general form of Chou's pseudo-amino acid composition for large-scale protein datasets, Int J Mol Sci 15:3495-3506, 2014.

20. Guo SH, Deng EZ, Xu LQ, Ding H, iNuc-PseKNC: A sequence-based predictor for predicting nucleosome positioning in genomes with pseudo k-tuple nucleotide composition, Bioinformatic 30:1522-1529, 2014.

21. Gupta K, Thomas D, Vidya SV, Venkatesh KV, Ramakumar S, Detailed protein sequence alignment based on Spectral Similarity Score (SSS), BMC Bioinformatics 6:105, 2005.

22. Jia J, Liu Z, Xiao X, iPPI-Esml: An ensemble classifier for identifying the interactions of proteins by incorporating their physicochemical properties and wavelet transforms into PseAAC, J Theor Biol 377:47-56, 2015. 
23. Kawashima S, et al., AAindex: Amino acid index database, progress report 2008, Nucl Acids Res 36:D202-D205, 2008.

24. Kiang YS, The biological functions of low-frequency phonons: 5. A phenomenological theory, Biophys Chem 22:219-235, 1985.

25. Lin H, Deng EZ, Ding H, iPro54-PseKNC: A sequence-based predictor for identifying sigma-54 promoters in prokaryote with pseudo k-tuple nucleotide composition, Nucl Acids Res 42:12961-12972, 2014.

26. Liu H, Wang M, Low-frequency Fourier spectrum for predicting membrane protein types. Biochem Biophys Res Commun 336:737-739, 2005.

27. Liu H, Yang J, Wang M, Using Fourier spectrum analysis and pseudo amino acid composition for prediction of membrane protein types, Protein $J$ 24:385-389, 2005.

28. Liu B, Wang X, Zou Q, Dong Q, Chen Q, Protein remote homology detection by combining Chou's pseudo amino acid composition and profile-based protein representation, Mol Informatics 32:775-782, 2013.

29. Liu B, Xu J, Lan X, Xu R, Zhou J, iDNA-Prot-dis: Identifying DNA-binding proteins by incorporating amino acid distance-pairs and reduced alphabet profile into the general pseudo amino acid composition, PLoS ONE 9:e106691, 2014.

30. Liu B, Zhang D, Xu R, Xu J, Wang X, Chen Q, Combining evolutionary information extracted from frequency profiles with sequence-based kernels for protein remote homology detection, Bioinformatics 30:472-479, 2014.

31. Liu B, Xu J, Fan S, Xu R, Jiyun Zhou J, Wang X, PseDNA-Pro: DNA-binding protein identification by combining Chou's PseAAC and physicochemical distance transformation, Mol Informatics 34:8-17, 2015.

32. Liu B, Chen J, Wang X, Protein remote homology detection by combining Chou's distance-pair pseudo amino acid composition and principal component analysis, Mol Genet Genom 2015, doi: 10.1007/s00438-00015-01044-00434.

33. Liu B, Fang L, Liu F, Wang X, Identification of real microRNA precursors with a pseudo structure status composition approach, PLoS ONE 10:e0121501, 2015.

34. Liu B, Fang L, Liu F, iMiRNA-PseDPC: MicroRNA precursor identification with a pseudo distance-pair composition approach, J Biomol Struct Dyn 2015, doi:10.1080/ 07391102.07392015.01014422.

35. Liu B, Liu F, Fang L, repDNA: A Python package to generate various modes of feature vectors for DNA sequences by incorporating user-defined physicochemical properties and sequence-order effects, Bioinformatics 31:1307-1309, 2015.

36. Liu B, Liu F, Fang L, Wang X, repRNA: A web server for generating various feature vectors of RNA sequences, Mol Genet Genom 2015, doi:10.1007/s00438-015-1078-7.

37. Liu B, Liu F, Wang X, Chen J, Fang L, Chou KC, Pse-in-One: A web server for generating various modes of pseudo components of DNA, RNA, and protein sequences, $\mathrm{Nucl}$ Acids Res 43:65-71, 2015.

38. Liu Z, Xiao X, Qiu WR, iDNA-Methyl: Identifying DNA methylation sites via pseudo trinucleotide composition, Anal Biochem 474:69-77, 2015.

39. Murray KB, Gorse D, Thornton JM, Wavelet transforms for the characterization and detection of repeating motifs, J Mol Biol 316:341-363, 2002.

40. Nakashima H, Nishikawa K, Ooi $\mathrm{T}$, The folding type of a protein is relevant to the amino acid composition, J Biochem 99:153-162, 1986.

41. Nanni L, Brahnam S, Lumini A, Wavelet images and Chou's pseudo amino acid composition for protein classification, Amino Acids 43:657-665, 2012.

42. Oppenheim AV, Schafer RW, Discrete-Time Signal Processing, Prentice-Hall, 3rd Edition, 2009. 
43. Peinado AM, Sanchez V, Perez-Cordoba JL, De la Torre A, HMM-based channel error mitigation and its application to distributed speech recognition, Speech Communication 41:549-561, 2003.

44. Pirogova E, Akay M, Cosic I, Investigating the interaction between oncogene and tumor suppressor protein, IEEE Trans Inf Technol Biomed 13:10-15, 2009.

45. Plotz T, Fink GA, Pattern recognition methods for advanced stochastic protein sequence analysis using HMMs, Pattern Recognition 39:2267-2280, 2006.

46. Punta M, et al., The Pfam protein families database, Nucl Acids Res 40:D290-D301, 2012.

47. Qi ZH, Jin MZ, Li SL, Feng J, A protein mapping method based on physicochemical properties and dimension reduction, Comput Biol Med 57:1-7, 2015.

48. Qiu J, Liang R, Zou X, Mou J, Prediction of protein secondary structure based on continuous Wavelet transform, Talanta 61:285-293, 2003.

49. Qiu JD, Huang JH, Liang RP, Lu XQ, Prediction of G-protein-coupled receptor classes based on the concept of Chou's pseudo amino acid composition: An approach from discrete wavelet transform, Anal Biochem 390:68-73, 2009.

50. Qiu JD, Suo SB, Sun XY, Shi SP, Liang RP, OligoPred: A web-server for predicting homo-oligomeric proteins by incorporating discrete wavelet transform into Chou's pseudo amino acid composition, J Mol Graph Model 30:129-134, 2011.

51. Qiu WR, Xiao X, iRSpot-TNCPseAAC: Identify recombination spots with trinucleotide composition and pseudo amino acid components, Int J Mol Sci 15:1746-1766, 2014.

52. Qiu WR, Xiao X, Lin WZ, iUbiq-Lys: Prediction of lysine ubiquitination sites in proteins by extracting sequence evolution information via a grey system model, J Biomol Struct Dyn 33:1731-1742, 2015.

53. Ravi N, Prediction of biologically active regions in protein sequences via best basis selection, 2010 Conf Record of the Forty Fourth Asilomar Conf Signals, Systems and Computers, pp. 1751-1755, 2010.

54. Sekhar S, Panda G, Efficient localization of hot spots in proteins using a novel s-transform based filtering approach, IEEE-ACM Trans Comput Biol Bioinform 8:1235-1246, 2011.

55. Sun XY, Shi SP, Qiu JD, Suo SB, Huang SY, Liang RP, Identifying protein quaternary structural attributes by incorporating physicochemical properties into the general form of Chou's PseAAC via discrete wavelet transform, Mol Biosyst 8:3178-3184, 2012.

56. Trad CH, Fang Q, Cosic I, The resonant recognition model (RRM) predicts amino acid residues in highly conserved regions of the hormone prolactin (PRL), Biophys Chem 84:149-157, 2000.

57. Xiao X, Min JL, Lin WZ, Liu Z, iDrug-Target: Predicting the interactions between drug compounds and target proteins in cellular networking via the benchmark dataset optimization approach, J Biomol Struct Dyn 2014, doi: 10.1080/07391102.07392014. 07998710 .

58. Zhang S, Wang T, Feature analysis of protein structure by using discrete Fourier transform and continuous wavelet transform, J Math Chem 46:562-568, 2009. 


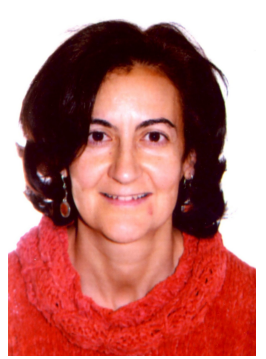

Victoria Sanchez received the M.Sc. and the Ph.D. degrees from the University of Granada, Granada, Spain, in 1988 and 1995, respectively.

In 1988, she joined the Signal Theory, Networking and Communications Department of the University of Granada where she is currently a member of the research group on Signal Processing, Multimedia Transmission and Speech/Audio Technologies. During 1991, she was visiting with the Electrical Engineering Department, University of Sherbrooke, Canada. Since 1997, she is an Associate Professor at the University of Granada.

Her research interests include multimedia transmission, speech and audio processing and, more recently, signal processing for genomics and proteomics. She has authored over 60 journal articles and conference papers in these fields.

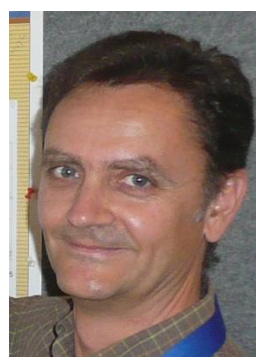

Antonio M. Peinado received the M.Sc. and Ph.D. degrees in physics from the University of Granada, Granada, Spain, in 1987 and 1994, respectively.

Since 1988, he has been with the University of Granada, where he has led several research projects on the areas of signal processing and transmission. In 1989, he was a Consultant with the Speech Research Department, AT\&T Bell Labs, Murray Hill, NJ, USA. He holds the position of Full Professor with the Department of Signal Theory, Networking and Communications of the University of Granada since 2010 and is currently head of the research group on Signal Processing, Multimedia Transmission and Speech/Audio Technologies (SigMAT). He is the author of numerous publications and coauthor of the book Speech Recognition Over Digital Channels (Wiley, New York, NY, USA: 2006).

His current research interests are focused on robust speech recognition and transmission, robust image/video transmission, and ultrasound signal processing. He is a Senior Member of the Institute of Electrical and Electronics Engineers (IEEE). 


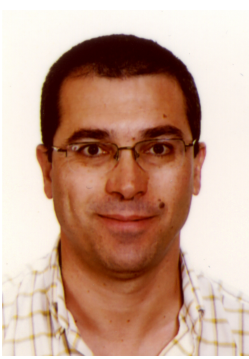

Jose L. Pérez-Córdoba received the Ph.D. degree in physics from the University of Granada, Granada, Spain, in 2000.

Currently, he is an Associate Professor at the Department of Signal Theory, Networking and Communications, University of Granada and a member of the research group on Signal Processing, Multimedia Transmission and Speech/Audio Technologies (SigMAT). From 1993 to 1994, he did a research stay at the System Research Institute, University of Maryland, College Park, where he was involved in joint source-channel coding research. From 2001 to 2002, he was a Visiting Researcher with the University of Almeria, Almeria, Spain, working on joint source-channel coding applied to image processing.

His research interests include speech coding and transmission and robust speech recognition.

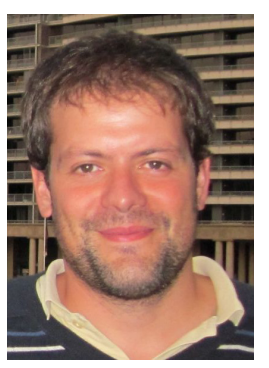

Angel M. Gómez received the M.Sc. and Ph.D. degrees in computing science from the University of Granada, Granada, Spain, in 2001 and 2006, respectively.

During 2004 and 2010, he was visiting with the Speech, Language, and Music group from the University of East Anglia, UK and the Speech Processing Laboratory from the University of Griffith, Australia, respectively. Since 2006, he has been an Assistant Professor at the Department of Signal Theory, Networking and Communications of the University of Granada. He is currently a member of the research group on Signal Processing, Multimedia Transmission and Speech/Audio Technologies (SigMAT).

His research in interests are in robust speech recognition and coding, and signal processing. Dr. Gómez has served as a reviewer for several international journals and conferences. 